\title{
Genetic effects have a dominant role on poor responses to infant vaccination to hepatitis $B$ virus
}

\author{
Kai Yan ${ }^{1,2}$, Wenping $\mathrm{Cai}^{3}$, Fang $\mathrm{Cao}^{2}$, $\mathrm{He} \mathrm{Sun}^{4}$, Shaoke $\mathrm{Chen}^{2}$, Ruiwei $\mathrm{Xu}^{2}$, Xin $\mathrm{Wei}^{5}$, Xiaoxiang Shi ${ }^{6}$ \\ and Weili Yan $^{1}$
}

The objective of this study was to investigate the overall contribution of genetic and environmental effects on poor response to hepatitis B virus (HBV) vaccination in Chinese infants. One-year-old healthy twins were recruited from child-care settings. Parental factors, neonates' condition at birth, postnatal infant feeding history and growth measurements during the 12 months were investigated by conducting an interview and checking the medical records. HBV-related markers were examined at 1 year of age. Heritability of surface antibody to HBV (anti-HBs) concentrations (ordinal variable) among twins was estimated using MX software. The role of perinatal environmental factors on poor vaccine response (anti-HBs $<100 \mathrm{mlU} \mathrm{ml}^{-1}$ ) was analyzed using XTGEE (fit population-averaged panel-data models by using GEE) programs. Overall, 172 out of 225 recruited twin pairs were analyzed for heritability, including 82 pairs $(47.67 \%)$ of monozygotic twins and 90 pairs of dizygotic twins, which consisted 43 pairs of $(25.0 \%)$ opposite sex twins, 29 pairs of male twins and 18 pairs of female twins. Seventy-one (19.9\%) of 370 twins showed poor responses to HBV vaccine. An additive genetic ( 0.91 of the variance)—random environmental $(0.09$ of the variance)-model best fit the variation of anti-HBs response. Risk factor analysis showed that with a smoking father and low birth weight, the infants were associated with an increased risk of poor response to HBV vaccination (odds ratio $(\mathrm{OR})=4.50,95 \%$ confidence interval $(\mathrm{Cl}): 2.52-8.03$ and $\mathrm{OR}=2.55,95 \% \mathrm{Cl}: 1.33-4.87$, respectively). Higher Apgar score and gaining more body weight in the first year of life reduced this risk. Genetic factors have a dominant role in determining infant $\mathrm{HBV}$ vaccination responses $(91 \%)$ compared with perinatal environmental factors.

Journal of Human Genetics (2013) 58, 293-297; doi:10.1038/jhg.2013.18; published online 14 March 2013

Keywords: Chinese; genetics; HBV; infant; twin study; vaccine response

\section{INTRODUCTION}

Infant hepatitis B virus (HBV) vaccination, as the most effective way to prevent HBV infection, ${ }^{1-3}$ was begun in China in 1992 as part of a national neonatal vaccination program. HBV immunization was administered to neonates at birth, at the first month and at the sixth month (0-1-6 program). It was reported by several studies that $10-15 \%$ of infants have a poor response to vaccination ${ }^{4,5}$ (including nonresponse that is defined as peak surface antibody to HBV (anti$\mathrm{HBs}$ ) antibody concentration below $10 \mathrm{mIU} \mathrm{ml}^{-1}$, and low response that is defined as anti-HBs concentration between $10-100 \mathrm{mIU} \mathrm{ml}^{-1}$ ). This poor response rate may increase with age. Low responders may remain susceptible to $\mathrm{HBV}$ infection as their antibody titers decline. Previous studies reported that both environmental and genetic factors contribute to vaccine responses; ${ }^{6,7}$ however, determinants of poor response have not been well characterized. Few studies identify risk factors that influence vaccine responses in infants. ${ }^{8}$ The effect of genetic or individual environmental factors on vaccine response remains confounded by differences in study subjects, method of vaccination, outcome measurements and analytical methods. By using a 1-year-old healthy twin infant sample, who completed full-course HBV vaccination programs from birth, the current study aims to systematically investigate the overall contribution of genetic and environmental effects on infant HBV vaccine responses and possible perinatal environmental risk factors.

\section{MATERIALS AND METHODS}

Ethic statements

The study protocols and consent procedure were approved by The Medical Ethic Committee of Children's Hospital of Fudan University. Written informed consent forms were obtained from parents on the behalf of the infant participants involved in our study. The study was conducted in accordance with the guidelines proposed in the World Medical Association Declaration of Helsinki.

\section{Study subjects}

Twin sample was for classical twin heritability estimation of poor vaccine responses. All subjects were recruited at their 1-year-old regular physical

\footnotetext{
${ }^{1}$ Department of Clinical Epidemiology, Children's Hospital of Fudan University, Shanghai, China; ${ }^{2}$ Department of Epidemiology and Statistics, Xinjiang Medical University, Urumqi, China; ${ }^{3}$ Department of Child Care, Children's Hospital of Urumqi City, Urumqi, China; ${ }^{4}$ Department of Child Care, People's Hospital of Xinjiang Uygur Autonomous Region, Urumqi, China; ${ }^{5}$ Department of Child Care, The First Teaching Hospital of Xinjiang Medical University, Urumqi, China and 6 Department of Child Care, Xinjiang General Hospital of Xinjiang Military Command, Urumqi, China

Correspondence: Professor W Yan, Department of Clinical Epidemiology, Children's Hospital of Fudan University, 399 Wanyuan Road, Shanghai 201102, China. E-mail: yanwl@fudan.edu.cn
}

Received 29 January 2013; revised 15 February 2013; accepted 15 February 2013; published online 14 March 2013 
examination performed at child-care settings of five comprehensive hospitals in Urumqi city, Xinjiang Uygur Autonomous Region, China. Children underwent $\mathrm{HBV}$ vaccination at birth, at 1 month and at 6 months. Five microgram recombinant HBV vaccine (KT60,2004L00065, recommended by the Chinese Ministry of Health, manufactured by Kangtai Biological Product, Shenzhen, Guangdong, China) were administered at each vaccination.

Inclusion criteria were twin infants with alive co-twins, who completed HBV full-course vaccination by the $0-1-6$ program with serological antibody concentration (anti-HBs) examined at age of 1 year ( \pm 1 month), who were of Han or Uygur ethnicity, whose mother had complete perinatal examination medical records and who had complete records of regular physical examination from birth to 1 year of age. Infants who had severe birth defects, history of severe infection, positive HBV antigen test or maternal history of HBV infection were excluded.

\section{Perinatal data collection}

Detailed data were obtained from the mother and father of the infants, including demographic information, history of noncommunicable chronic disease, infections during pregnancy, allergy to drugs or foods, HBV infection, HBV vaccination, cigarette smoking and alcohol consumption. Smoking history was obtained by asking 'Do you smoke?', followed by three options: never smoke, smoke occasionally or smoke every day. Maternal gestational weight gain, infant feeding history and infant growth measurements at four time points, the forty-second day and at the end of the third, sixth and twelfth month in the first year of life were obtained by interviewing parents and from medical records. A venous blood sample $(1 \mathrm{ml})$ was drawn from infants for serum HBV biomarker examination and DNA extraction

\section{Testing for HBV markers}

HBV markers were qualitatively and quantitatively examined in the Central Laboratory of the First Teaching Hospital of Xinjiang Medical University, under regular quality control. Whole blood $(2 \mathrm{ml})$ was collected from participants using nonanticoagulant tubes (Becton Dickinson, Franklin Lakes, NJ, USA), centrifuged at 3000 r.p.m. for $10 \mathrm{~min}$, separated within $3 \mathrm{~h}$ and stored at $-20^{\circ} \mathrm{C}$. Qualitative HBV markers (Abbott, Delkenheim, Germany), including $\mathrm{HBs}$ antigen, anti-HBs and anti-HBc, were examined using enzymelinked immunosorbent assay kits (Auszyme Monoclonal, AUSAB, Corzyme; Abbott Laboratories, North Chicago, IL, USA). Recombinant HBV surface antigen (HBsAg; $100 \mu \mathrm{l} ; 1 \mu \mathrm{g} \mathrm{ml}^{-1}$ ) in $1 \mathrm{~m}$ bicarbonate buffer ( $\mathrm{pH}$ 8.2) was coated onto microtiter plates and incubated overnight at $4{ }^{\circ} \mathrm{C}$. The plates were then washed in phosphate-buffered saline and incubated overnight in phosphate-buffered saline buffer containing $4 \%$ bovine serum albumin at $4{ }^{\circ} \mathrm{C}$. After two washes, $100 \mu \mathrm{l}$ of peroxidase IgG, diluted 1:4000, was added and the plates incubated were for $1 \mathrm{~h}$ at $37^{\circ} \mathrm{C}$. Following a phosphate-buffered saline wash step, $100 \mu \mathrm{l}$ of substrate was added and the plates incubated for $30 \mathrm{~min}$ at $37^{\circ} \mathrm{C}$, and then stopped with $50 \mu \mathrm{l}$ of $1 \mathrm{M} \mathrm{H}_{2} \mathrm{SO}_{4}$. An optical reading of the plates was performed at $450 \mathrm{~nm}$, using a spectrophotometer. Anti-HBc and HBs-Ag concentrations were expressed as the optical density and the sample-to-cutoff ratio. Anti-HBs were examined quantitatively by enzymelinked immunofluorescent assay using Architect 11000 kits (Abbott), according to the manufacturer's recommendations. Reactivity to $\mathrm{HBsAg}$ was visualized with a mouse anti-human IgG horseradish peroxidase (HRP) conjugate and HRP substrate. The results were interpreted with a computer-assisted lightintensity analyzer for each dot.

\section{Definition of poor $\mathrm{HBV}$ vaccine responders}

HBV biomarkers, including quantitative anti-HBs and regular five qualitative markers, were examined for venous blood 6 months after the third injection. Poor responses were defined as anti-HBs $<100 \mathrm{mIU} \mathrm{ml}^{-1}$ in this study. To exclude occult infection of HBV, 25 and 55 twin subjects were dropped because of positive serum HBsAg tests and reported maternal HBV infection history, respectively.

\section{Zygosity determination}

Zygosity of twins was determined using DNA-based microsatellite markers (PowerPlex 16, Promega, Madison, WI, USA) based on the standardized protocols from the manufacture (PowerPlex Matrix Standard 310). Negative controls and positive controls were also determined for quality control of the assay. Gender of the subjects was confirmed by conducting an interview and performing genetic tests. Zygosity of 192 pairs of twins was successfully determined.

\section{Statistical analysis}

Heritability analysis. The overall contribution of genetic and environmental effects on HBV vaccine response was estimated using classical MX path analyses ${ }^{9}$ among 172 complete pairs of twins with complete zygosity and vaccine response data. MX path analysis fits models to phenotype (anti-HBs concentration were treated as ordinal variable defined as no response, low response or normal response, using cutoff points of 10 and $100 \mathrm{mIU} \mathrm{ml}^{-1}$ ) and determines the relative contribution of additive genetic variance (A), dominant genetic variance $(\mathrm{D})$, common environmental variance $(\mathrm{C})$ and random environmental variance (E). We initially fitted a model that allowed for ACE contributions. The fit of the data was then compared using ACE, AE and $\mathrm{CE}$ models. Results show heritability under the ACE model, unless the AE model provided a significantly better fit to the data than ACE $(P<0.1){ }^{9}$

Risk factor analysis. General descriptive and inferential statistical analyses were performed using STATA 11.0 (Stata, College Station, TX, USA) among 370 twin subjects with complete zygosity, questionnaire data and anti-HBs data. A $P$-value $<0.05$ was used to indicate statistical significance. As anti-HBs antibody did not meet normal distribution with censoring values at $1000 \mathrm{mIU} \mathrm{ml}^{-1}$, the response to $\mathrm{HBV}$ vaccine was defined as binomial: 1 for poor response (anti-HBs antibody $<100 \mathrm{mIU} \mathrm{ml}^{-1}$ ) and 0 for normal response (anti-HBs antibody $\geqslant 100 \mathrm{mIU} \mathrm{ml}^{-1}$ ), for risk factor analysis and heritability analysis. The XTGEE (fit population-averaged panel-data models by using GEE) program was applied to adjust the within-twin relatedness during the

\section{Table 1 General characteristics of study subjects}

\begin{tabular}{|c|c|c|c|c|}
\hline Characteristics & \multicolumn{2}{|c|}{$\begin{array}{l}\text { Twin subjects } \\
\text { (individuals) }\end{array}$} & $\begin{array}{c}\text { MZ twins } \\
\text { (pairs) }\end{array}$ & $\begin{array}{c}\text { DZ twins } \\
\text { (pairs) }\end{array}$ \\
\hline$N$ & \multicolumn{2}{|c|}{370} & 82 & 90 \\
\hline Male, $n$ & 217 & 58.65 & $51(62.2)$ & $50.5(56.1)$ \\
\hline ity, $n(\%)$ & 321 & & 73 & 78 (86.7) \\
\hline inge) & $36.7 \pm 2.1$ & $30-$ & $\begin{array}{l}36.7 \pm 2 \\
7(91\end{array}$ & $36.01 \pm 2.17$ \\
\hline $\begin{array}{l}\%) \\
\text { (range) }\end{array}$ & $2.5 \pm 0.5$ & $1.5-$ & $2.6 \pm 0.4$ & $2.47 \pm 0.48$ \\
\hline Low b & 159 & & 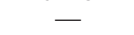 & - \\
\hline $\begin{array}{l}\text { Asphyxia at birth, } \\
n(\%)\end{array}$ & 40 & & - & - \\
\hline Apgar score (range) & $14 \pm 1.03$ & -10 & $9.1 \pm 1.2$ & $9.22 \pm 0.95$ \\
\hline $\begin{array}{l}\text { Infection at birth, } \\
n(\%)\end{array}$ & & & & \\
\hline $\begin{array}{l}\text { Father infected HBV, } \\
\text { pair (\%) }\end{array}$ & 21 & 11.08 & $10(12.2)$ & $9(10)$ \\
\hline $\begin{array}{l}\text { Father HBV vacci- } \\
\text { nated, pair (\%) }\end{array}$ & 62 & 33.51 & 32 (37.8) & $29(32.2)$ \\
\hline $\begin{array}{l}\text { Father smoker, } \\
\text { pair }(\%)\end{array}$ & 136 & 73.78 & $60(73.2)$ & $65(72.3)$ \\
\hline $\begin{array}{l}\text { Father alcohol } \\
\text { consumer, pair (\%) }\end{array}$ & 153 & 82.70 & $69(84.2)$ & $72(80)$ \\
\hline $\begin{array}{l}\text { Mother HBV } \\
\text { vaccinated, pair (\%) }\end{array}$ & 78 & 42.16 & $33(40.2)$ & $38(42.2)$ \\
\hline $\begin{array}{l}\text { Mother smoker, } \\
\text { pair (\%) }\end{array}$ & 1 & 0.54 & 0 & $1(1.1)$ \\
\hline $\begin{array}{l}\text { Mother alcohol } \\
\text { consumer, pair (\%) }\end{array}$ & 7 & 3.78 & $16(19.5)$ & $27(30)$ \\
\hline $\begin{array}{l}\text { Months of breast } \\
\text { feeding, months }\end{array}$ & $7.72 \pm 1.62$ & $0-11$ & $7.8 \pm 1.8$ & $7.7 \pm 1.5$ \\
\hline $\begin{array}{l}\text { Infections before } 1 \\
\text { year old, } n(\%)\end{array}$ & (6) & 0.27 & - & - \\
\hline $\begin{array}{l}\text { Weight gain at } \\
1 \text { year old, kg }\end{array}$ & $6.52 \pm 0.87$ & $4-9.3$ & $6.4 \pm 0.9$ & $6.6 \pm 0.8$ \\
\hline
\end{tabular}

Abbreviations: DZ, dizygotic; HBV, hepatitis B virus; MZ, monozygotic.

a Data analyses were performed in 370 twin subjects (individuals) after exclusion of positive maternal HBV infection $(n=55)$ or positive serological infant HBV antigen testing $(n=25)$. ${ }^{b}$ Computations were based on twin pairs valid for twin analysis inappropriate to be calculated as twin pairs. 
association between perinatal risk factors with the poor response to HBV vaccination. Risk factors covered maternal and paternal factors before and during pregnancy, birth outcomes, feeding and growth measurements of infant during the first 12 months. Independent variables included maternal age, maternal weight gain during pregnancy, maternal HBV infection history, HBV vaccination history of parents, parental smoking and alcohol consumption, birth weight, Apgar score (a commonly used simple and repeatable method to quickly and summarily assess the health of newborn children immediately after birth.), mode of delivery and infant body weight at four postnatal time points (at the forty-second day, third month, sixth month and twelfth month). For risk factor analysis for unrelated subjects in the singleton sample, vaccine response were treated as binomial variable and continuous variable respectively, multivariate logistic regression and tobit regression were performed for respectively. Risk estimates were reported as odds ratios and $95 \%$ confidence intervals.

\section{RESULTS}

\section{General characteristics of study subjects}

In total, 225 pairs (450 subjects) of twins were recruited. After excluding failure in zygosity determination ( $n=16$ subjects), positive

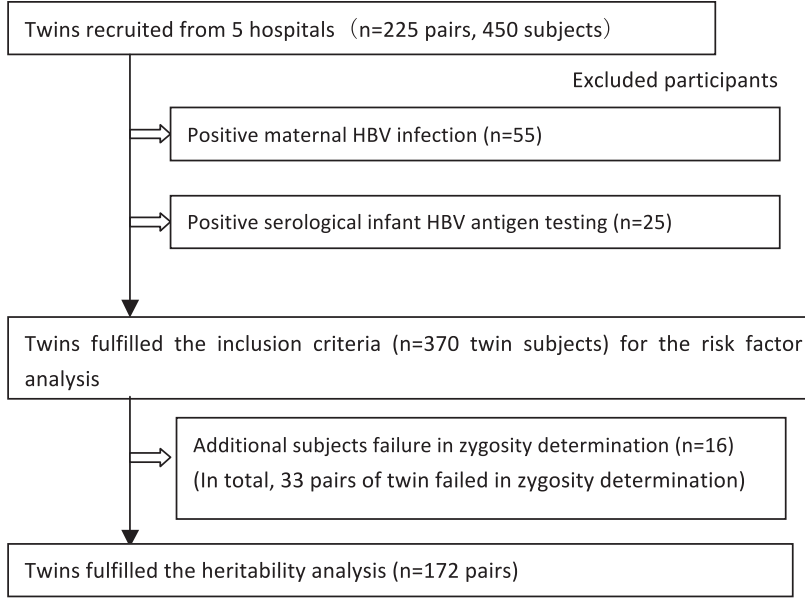

Figure 1 The flow chart of study subjects.

Table 2a Diverse response to $\mathrm{HBV}$ vaccine in $\mathrm{MZ}$ twins and $\mathrm{DZ}$ twins by sex

\begin{tabular}{|c|c|c|c|c|c|c|}
\hline \multirow[b]{2}{*}{ Anti-HBs, $m / \cup m I^{-1}$} & \multicolumn{3}{|c|}{ MZ twin 1, pairs (\%) } & \multicolumn{3}{|c|}{ DZ twin 1, pairs (\%) } \\
\hline & $<10$ & $10 \sim 100$ & $\geqslant 100$ & $<10$ & $10 \sim 100$ & $\geqslant 100$ \\
\hline \multicolumn{7}{|l|}{ Male } \\
\hline$<10$ & $38(95)$ & $2(5)$ & 0 & $18(75)$ & $3(12.5)$ & $3(12.5)$ \\
\hline$\geqslant 10$ and $<100$ & $4(50)$ & $4(50)$ & 0 & $3(60)$ & $2(40)$ & 0 \\
\hline$\geqslant 100$ & 0 & 0 & $3(100)$ & 0 & 0 & 0 \\
\hline
\end{tabular}

$\begin{aligned} & \text { Female } \\ & <10\end{aligned}$
$\begin{array}{lcccccc}\geqslant & 26(92.9) & 2(7.1) & 0 & 12(85.7) & 1(7.15) & 1(7.15) \\ \geqslant 100 & 1(50) & 1(50) & 0 & 2(100) & 0 & 0 \\ & 0 & 1(100) & 0 & 1(50) & 0 & 1(50)\end{array}$

\begin{tabular}{|c|c|c|c|c|c|}
\hline$<10$ & - & - & - & $30(909)$ & $3(9.1)$ \\
\hline$\geqslant 10$ and $<100$ & _- & - & - & $2(25)$ & $6(75)$ \\
\hline$\geqslant 100$ & - & - & - & $1(50)$ & $1(50)$ \\
\hline
\end{tabular}

Abbreviations: Anti-HBs, surface antibody to HBV; DZ, dizygotic; HBV, hepatitis B virus; MZ, monozygotic. maternal HBV infection history (25 subjects) and infant serological HBV-Ag examination test (55 subjects $\mathrm{HBsAg} \geqslant 0.105$ sample-tocutoff ratio), the general and clinical characteristics of 370 study subjects are shown in Table 1 . Seventy-one out of 370 twin subjects (19.19\%) were poor responders to HBV vaccine. The participants' flow chart was presented (Figure 1).

\section{Heritability of poor responses to infant $\mathrm{HBV}$ vaccination}

Heritability analysis was performed in 172 pair of twins with 82 pairs (47.67\%) of monozygotic (MZ) twins, including 29.65\% (51 pairs/ 172 pairs) male twins and $18 \%$ (31 pairs/172 pairs) female twins. Ninety pairs of dizygotic (DZ) twins consisted $25 \%$ of opposite sex (43 pairs ), $16.86 \%$ of males (29 pairs) and $10.47 \%$ of females (18 pairs). To test if sex had any effect on poor response to HBV vaccination, the concordance rate were compared between sex by $\mathrm{MZ}$ and DZ twins before the heritability analysis (Table 2a). The proportion of nonresponders, low responders and normal responders did not differ significantly between male subjects and female subjects, either in the Han or the Ugyur ethnic groups (Table 2b). The concordance rate of responses (ordinal) to HBV vaccine was marginally higher in MZ twins than that in DZ twins (Table 2c); however, it did not significantly differ between males and females in neither the MZ twins ( 0.882 vs $0.87, P=1$ Fisher's exact test) nor in the DZ twins ( 0.690 vs $0.722, P=0.812)$. Therefore, we did not test sex effect in MX modeling. The correlations of anti-HBs antibody levels within twin pairs were $r_{\mathrm{MZ}}=0.6534$ vs $r_{\mathrm{DZ}}=0.3489$ in $\mathrm{MZ}$ and DZ twins, respectively (Figure 2). As $r_{\mathrm{DZ}}>1 / 2 r_{\mathrm{MZ}}$, model fitting was performed starting with $\mathrm{ACE}, \mathrm{AE}$ and $\mathrm{CE}$ model (Table 3). It showed that $\mathrm{AE}$ model fitted best to the data. The estimated additive genetic effect and unique environmental effect was 0.9063 (95\% CI: 0.7561-0.9717) and 0.0937 (95\% CI: $0.0283-0.2440)$, respectively.

\section{Table 2b Diverse response to HBV vaccine by sex and ethnicity}

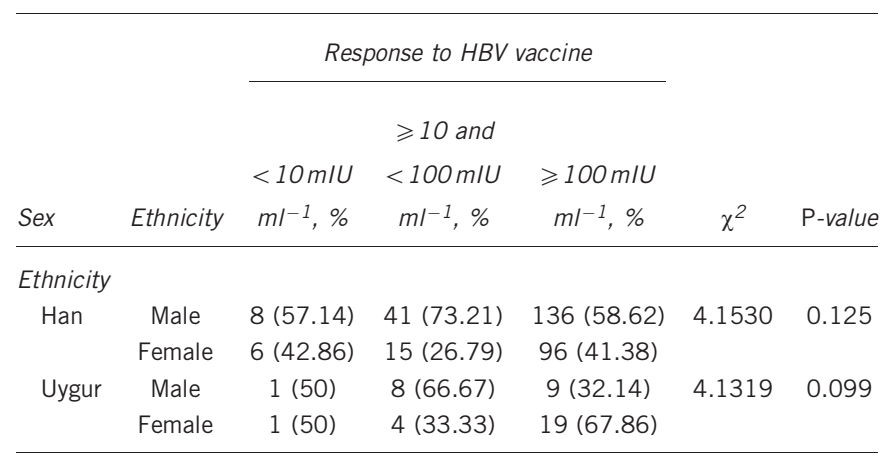

Abbreviation: HBV, hepatitis B virus.

Table 2c Diverse response to HBV vaccine in MZ twins and DZ twins

\begin{tabular}{|c|c|c|c|c|c|c|}
\hline \multirow{2}{*}{$\begin{array}{l}\text { Anti-HBs, } \\
m I \cup m I^{-1}\end{array}$} & \multicolumn{3}{|c|}{$\begin{array}{c}\text { MZ twin 1, } \\
\text { pairs (\%) }\end{array}$} & \multicolumn{3}{|c|}{$\begin{array}{l}\text { DZ twin 1, } \\
\text { pairs (\%) }\end{array}$} \\
\hline & $<10$ & $10 \sim 100$ & $\geqslant 100$ & $<10$ & $10 \sim 100$ & $\geqslant 100$ \\
\hline \multicolumn{7}{|l|}{ MZ twin2/DZ twin2 } \\
\hline$<10$ & $3(1.74)$ & $1(0.58)$ & 0 & $1(0.58)$ & $1(0.58)$ & $2(1.16)$ \\
\hline$\geqslant 10$ and $<100$ & 0 & $5(2.91)$ & $5(2.91)$ & 0 & $8(4.65)$ & 7 (4.07) \\
\hline$\geqslant 100$ & 0 & $4(2.33)$ & $64(37.21)$ & 4 (2.33) & $7(4.07)$ & $60(34.88)$ \\
\hline
\end{tabular}

Abbreviations: Anti-HBs, surface antibody to $\mathrm{HBV}$; DZ, dizygotic; $\mathrm{HBV}$, hepatitis $\mathrm{B}$ virus; $\mathrm{MZ}$, monozygotic

The concordance rate in MZ twins 0.878 (72/82) is higher than that in DZ twins 0.767 (69/ 90), $P=0.058$ 


\section{Risk factors to poor vaccine responses}

Perinatal parental and infant risk factors were compared between vaccine normal responders and poor responders in twins (regardless the within-twin relatedness). We found that Uygur ethnicity, low birth weight, low Apgar score, smaller gestational age, asphyxia at birth, less weight gain before 1-year-old, less breast feeding and paternal HBV infection history were more common in poor responders than that in normal responders in twin subjects $(P \leqslant 0.015$; Table 4$)$. To adjust the relatedness within twin pairs, effects of above possible risk factors to the outcome were analyzed by using XTGEE programs. After manually model fitting, four risk factors remained significantly associated with the outcome (Table 5). It showed that smoking father increased the risk of poor $\mathrm{HBV}$ vaccine response $(\mathrm{OR}=3.5,95 \% \mathrm{CI}$ : 2.52-8.03). Infants born with low birth weight had higher risk to be poor responders to $\mathrm{HBV}$ vaccine compared with those born with normal weight $(\mathrm{OR}=2.55,95 \% \mathrm{CI}$ : $1.33-4.87)$. Every $1 \mathrm{~kg}$ of increment of weight gain in the first year of life reduced the risk of poor response to HBV vaccine by $52 \%$. Increment in Apgar score by 1 at birth decreased the risk by $1 / 2$ (Table 5). Same analyses were performed in subgroup of twins with normal birth weight only, showing the similar association between the rests of three indicated risk factors above with the outcome. The OR (95\% CI) for smoking father, first-year weight gain after birth and Apgar score were 4.13 (1.97-8.67), $0.53(0.30-0.93)$ and $0.58(0.39-0.87)$, respectively.

\section{DISCUSSION}

The current study fits an AE model for the phenotype and poor response to infant $\mathrm{HBV}$ vaccination; it also reports a heritability of the phenotype of 0.91 in Chinese 1-year-old infants, indicating that the HBV vaccine responses are dominantly determined by a genetic effect (0.91) and rest of the variation (0.09) is determined by unshared

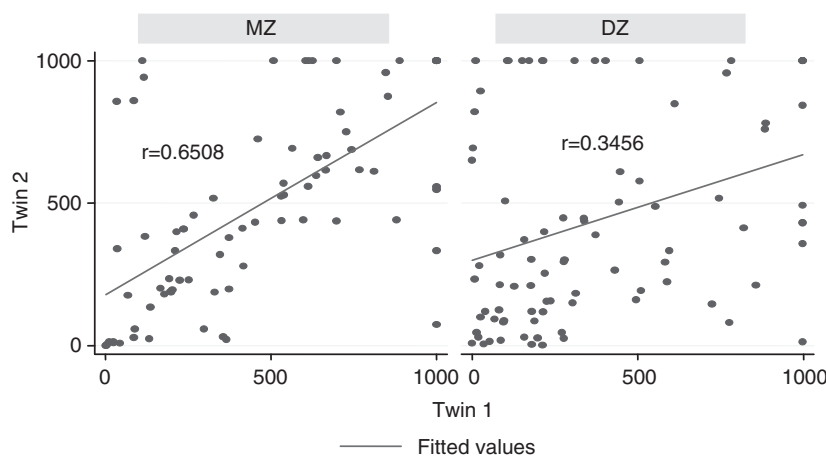

Figure 2 Correlations of surface antibody to HBV (anti-HBs) concentration within monozygotic (MZ) twins and dizygotic (DZ) twins. The correlation coefficient of anti-HBs levels within twin 1 and twin 2 was $r=0.6508$ in $\mathrm{MZ}$ twins and $r=0.3456$ in DZ twins, respectively. A full color version of this figure is available at the Journal of Human Genetics journal online individual environmental factors. The estimation of heritability of poor response to $\mathrm{HBV}$ vaccine reported by the current twin analysis is higher than previous twin studies; for example, 0.60 for anti-HBs titer reported by Höhler et al. ${ }^{6}$ based on 202 pairs of adult twins, and 0.77 for anti-HBs concentration reported by Newport et al. ${ }^{7}$ based on 5month-old infants vaccinated at birth. Similar to the previous twin studies, the best-fitted model includes additive genetic effect and unique environment effect only (AE model).

Heritability is partly dependent on the prevalence of environmental risk factors in the study sample; in populations with a higher environmental exposure, the heritability will be lower. ${ }^{10}$ The higher heritability of the HBV vaccine response found in infant twins than that in adult twins may indicate stronger genetic effect on the outcome. With this motivation, this study for the first time evaluates the heritability of vaccine response in Chinese infants after the uniform infant $\mathrm{HBV}$ vaccination program. In a previous twin study, which also used infant subjects, ${ }^{7}$ the responses of antibody to three-dose HBV vaccination (by $0-2-4$ program) in infants aged 5 months was determined by additive genetic effect (0.77) and unshared environmental factors $(0.23) .^{7}$ The differences in general characteristics of the study subjects of the two infant twin studies, such as age, ethnicity, vaccine, duration of anti-HBs examination after vaccination and nutrition status, may influence the variation of antiHBs levels and may contribute to the different estimation of the overall genetic effect on the phenotype. The twins of the current study, with average birth weight of $2.5 \mathrm{~kg}$, gestational age of 36.7 weeks and average Apgar score of 9.1, are relatively healthy and have

Table 4 Risk factors to poor response to $\mathrm{HBV}$ vaccination: univariate analysis ${ }^{\mathrm{a}}$

\begin{tabular}{lcccc}
\hline Subject characteristics & $\begin{array}{c}\text { Normal } \\
\text { response }\end{array}$ & $\begin{array}{c}\text { Poor } \\
\text { response }\end{array}$ & $\chi^{2 / t}$ & P-value \\
\hline$n(\%)$ & $299(80.80)$ & $71(19.19)$ & - & - \\
Han ethnicity, $n(\%)$ & $265(88.63)$ & $56(78.87)$ & 4.75 & 0.029 \\
Birth weight, kg & $2.55 \pm 0.44$ & $2.36 \pm 0.51$ & 3.2929 & 0.0005 \\
Apgar score & $9.29 \pm 0.86$ & $8.52 \pm 1.41$ & 5.9229 & $<0.0001$ \\
Gestational age, weeks & $36.42 \pm 2.20$ & $35.8 \pm 1.96$ & 2.165 & 0.0155 \\
Asphyxia at birth, $n(\%)^{b}$ & $10(3.34)$ & $13(18.31)$ & - & $<0.0001$ \\
Weight gain in first year, kg & $6.58 \pm 0.91$ & $6.29 \pm 0.67$ & 2.48545 & 0.0067 \\
Brest feeding, months & $7.90 \pm 1.51$ & $7.21 \pm 2.01$ & 3.2237 & 0.0007 \\
Paternal HBV vaccination, $n$ & $190(63.55)$ & $56(78.87)$ & 6.05 & 0.014 \\
$(\%)$ & & & & \\
Paternal smoking, $n(\%)^{b}$ & $205(68.56)$ & $68(95.77)$ & - & $<0.0001$ \\
Paternal alcohol consumption, & $239(79.93)$ & $67(94.37)$ & 8.35 & 0.004 \\
$n(\%)$ & & & &
\end{tabular}

Abbreviation: HBV, hepatitis B virus.

a Univariate analysis was applied in twins by neglecting within-twin relatedness.

bFisher's exact test was performed.

Table 3 Heritability analysis

\begin{tabular}{|c|c|c|c|c|c|c|c|}
\hline Model & $A(95 \% C l)$ & C $(95 \%$ CI) & $E(95 \% C l)$ & RMSEA & $A / C$ & $\chi^{2}$ & P-value \\
\hline ACE & $0.8523(0.7735,0.9281)$ & $0.0520(0.000,0.1743)$ & $0.0957(0.0301,0.2578)$ & 0.035 & -10.47 & 0.03 & 0.866 \\
\hline$A E$ & $0.9063(0.7561,0.9717)$ & 0 & $0.0937(0.0283,0.2440)$ & 0.030 & -12.44 & - & - \\
\hline CE & 0 & $0.3520(0.2812,0.4193)$ & $0.6480(0.5761,0.7254)$ & 0.004 & 0 & 8.61 & 0 \\
\hline$E$ & 0 & 0 & 1 & 0.173 & 37.84 & 14.27 & 0 \\
\hline
\end{tabular}

Abbreviations: A, additive genetic variance; AIC, Akaike information criterion; anti-HBs, surface antibody to HBV; D, dominant genetic variance; C, common environmental variance; $\mathrm{E}$, random environmental variance; $\mathrm{Cl}$, confidence interval; RMSEA, root mean square error of approximation

Modeling fitting for ACE, AE and E models: performance of genetic models ( $n=172$ pairs). Note: anti-HBs were defined as ordinal variable. 0,1 and 2 for anti-HBs $\geqslant 100,10-100$ and $<10 \mathrm{mlU} \mathrm{ml}^{-1}$ 
Table 5 Multivariate analysis of determinants from parents and children to poor response to $\mathrm{HBV}$ vaccination in twins

\begin{tabular}{|c|c|c|c|c|c|}
\hline & & & $95 \%$ & $95 \%$ & \\
\hline Independent & & & $\mathrm{Cl}$ & $\mathrm{Cl}$ & \\
\hline variables & Coding & $O R$ & Lower & Upper & P-value \\
\hline Father smoking & $\begin{array}{c}\text { 0: Never, } 1 \text { : occasionally } \\
\text { smoke, 2: smoke every day }\end{array}$ & 4.50 & 2.52 & 8.03 & $<0.0001$ \\
\hline Low birth weight & 0: no, 1: yes & 2.55 & 1.33 & 4.87 & 0.005 \\
\hline $\begin{array}{l}\text { Weight gain in } \\
\text { first year, kg }\end{array}$ & - & 0.42 & 0.28 & 0.63 & $<0.0001$ \\
\hline Apgar score & & 0.54 & 0.40 & 0.71 & $<0.0001$ \\
\hline
\end{tabular}

Abbreviation: $\mathrm{Cl}$, confidence interval; OR, odds ratio; HBV, hepatitis $\mathrm{B}$ virus; XTGEE, fit population-averaged panel-data models by using GEE.

Wald's $\gamma^{2}(8)=55, P<0.0001$

$\mathrm{XTGEE}$ program was used to adjust within-twin relatedness.

low levels of unfavorable environmental exposures, which may be an explanation of the higher estimation of the additive genetic component.

The association between ethnicity and poor vaccine response indicated by univariate analysis without adjusting within-twin relatedness (Table 4) disappeared in multivariate analysis (Table 5). As the effective sample size was small for the Uygur ethnic group $(n=49$ subjects), we performed the risk factor analysis in limited extend in this subgroup by only including the four significant risk factors from the whole group analysis, showing that only smoking father and Apgar score remained significant or marginally significant $(\mathrm{OR}=12.32,95 \% \mathrm{CI}: 2.07-73.3$ for smoking father and $\mathrm{OR}=0.42$, 95\% CI: $0.178-1.006$ for Apgar score). There were no significant ethnic difference in mean birth weight, Apgar score or weight gain during the first year of life, whereas the rate of smoking father was higher in the Uygur subjects compared with the Han subjects (95.56\% vs $69.9 \%, P=0.001)$. Therefore, there is no sufficient evidence of ethnic difference between the Han and the Uygur infants in responses to infant HBV vaccination. Further study with larger sample size is expected to confirm the ethnic difference in vaccine responses.

Although numerous evidence support that genetic effect have dominant roles in immune responses to HBsAg, the effect of unshared environmental factors indicated by previous studies ${ }^{4,11,12}$ and the current study indicates that prevention of perinatal unfavorable risk factor may reduce the risk of poor vaccine responses.

The current study has some strength in design. First, high homogeneity of the phenotype variable - anti-HBs was from study subjects who received uniform infant HBV vaccination program and was determined in the qualified examination lab center. Second, extensive possible perinatal environmental risk factors related to poor vaccine responses are investigated in this study.

Limited information about paternal cigarette smoking is one limitation of the study. The amount of smoking is not available from smokers. The association between smoking father and poor response to $\mathrm{HBV}$ vaccination in infants needs confirmation in future studies. Although appropriate XTGEE program is used for adjustment of relatedness of twin subjects, risk factor analysis in unrelated twin sample is another weakness of the current study.

Combining the above evidence, we conclude that the HBV vaccine response in infants is dominantly determined by genetic effect by $91 \%$. The four nongenetic risk factors to poor vaccine response identified in the current study are modifiable by better comprehensive primary healthcare and prevention. A number of candidate gene studies and genome-wide association studies ${ }^{6,13-15}$ suggested numerous but inconsistent DNA sequence polymorphisms from human leukocyte antigen family genes and outside human leukocyte antigen family genes; the high heritability of the phenotype strongly tells the importance of future genetic studies to fully illustrate the underlying genetic factors that regulate infant HBV vaccine responses. Before genetic determinants were fully revealed, awareness and effort from society and individuals are needed to reduce the population rate of vaccine failure.

\section{CONFLICT OF INTEREST}

The authors declare no conflict of interest.

\section{ACKNOWLEDGEMENTS}

We are grateful to the twins and their families for participating this study. We also thank Lihua Yu and Xue Zhang from the Clinical Lab Center of the First Teaching Hospital of Xinjiang Medical University for their assistance in HBV biomarkers examination. We thank all investigators for their contribution in helping complete this study, but who are not listed in the author's list. This study was supported by the National Science Foundation of China (grant number 30960329) and Intramural funding of Children's Hospital of Fudan University.

1 Beasley, R. P., Hwang, L. Y., Lee, G. C., Lan, C. C., Roan, C. H., Huang, F. Y. et al. Prevention of perinatally transmitted hepatitis $B$ virus infections with hepatitis $B$ virus infections with hepatitis B immune globulin and hepatitis B vaccine. Lancet 2 , 1099-1102 (1983).

2 Arevalo, J. A. \& Washington, A. E. Cost-effectiveness of prenatal screening and immunization for hepatitis B virus. JAMA 259, 365-369 (1988).

3 Van Damme, P., Kane, M. \& Meheus, A. Integration of hepatitis B vaccination into national immunisation programmes. Viral. Hepatitis. Prevention. Board. BMJ 314, 1033-1036 (1997).

4 Roome, A. J., Walsh, S. J., Cartter, M. L. \& Hadler, J. L. Hepatitis B vaccine responsiveness in Connecticut public safety personnel. JAMA 270, 2931-2934 (1993).

5 Rosman, A. S., Basu, P., Galvin, K. \& Lieber, C. S. Efficacy of a high and accelerated dose of hepatitis $\mathrm{B}$ vaccine in alcoholic patients: a randomized clinical trial. Am. J. Med. 103, 217-222 (1997).

6 Hohler, T., Reuss, E., Evers, N., Dietrich, E., Rittner, C., Freitag, C. M. et al. Differential genetic determination of immune responsiveness to hepatitis B surface antigen and to hepatitis A virus: a vaccination study in twins. Lancet 360, 991-995 (2002).

7 Newport, M. J., Goetghebuer, T., Weiss, H. A., Whittle, H., Siegrist, C. A. \& Marchant, A. Genetic regulation of immune responses to vaccines in early life. Genes Immun. 5, 122-129 (2004).

8 Losonsky, G. A., Wasserman, S. S., Stephens, I., Mahoney, F., Armstrong, P., Gumpper, $\mathrm{K}$. et al. Hepatitis $\mathrm{B}$ vaccination of premature infants: a reassessment of current recommendations for delayed immunization. Pediatrics 103, E14 (1999).

9 Neale, M. C., Boker, S. M., Xie, G. \& Maes, H. H. Mx: Statistical Modeling (Department of Psychiatry, Virginia Commonwealth University, Richmond, VA, 1999).

10 Newport, M. J., Goetghebuer, T. \& Marchant, A. Hunting for immune response regulatory genes: vaccination studies in infant twins. Expert. Rev. Vaccines 4, 739-746 (2005).

11 Lau, Y. L., Tam, A. Y., Ng, K. W., Tsoi, N. S., Lam, B., Lam, P. et al. Response of preterm infants to hepatitis B vaccine. J. Pediatr. 121, 962-965 (1992).

12 Freitas da Motta, M. S., Mussi-Pinhata, M. M., Jorge, S. M., Tachibana Yoshida, C. F. \& Sandoval de Souza, C. B. Immunogenicity of hepatitis B vaccine in preterm and full term infants vaccinated within the first week of life. Vaccine 20, 15571562 (2002).

13 Hennig, B. J., Fielding, K., Broxholme, J., Diatta, M., Mendy, M., Moore, C. et al. Host genetic factors and vaccine-induced immunity to hepatitis B virus infection. PLoS One 3, e1898 (2008).

14 Davila, S., Froeling, F. E., Tan, A., Bonnard, C., Boland, G. J., Snippe, H. et al. New genetic associations detected in a host response study to hepatitis B vaccine. Genes Immun. 11, 232-238 (2010).

15 Png, E., Thalamuthu, A., Ong, R. T., Snippe, H., Boland, G. J. \& Seielstad, M. A genome-wide association study of hepatitis $\mathrm{B}$ vaccine response in an Indonesian population reveals multiple independent risk variants in the HLA region. Hum. Mol. Genet. 20, 3893-3898 (2011) 